\title{
Characterization and Pathogenicity of Fusicladium eriobotryae, the Fungal Pathogen Responsible for Loquat Scab
}

\author{
P. Sánchez-Torres, R. Hinarejos, and J. J. Tuset, Centro de Protección Vegetal y Biotecnología. Instituto Valen- \\ ciano de Investigaciones Agrarias (IVIA), Moncada-Valencia, Spain
}

\begin{abstract}
Sánchez-Torres, P., Hinarejos, R., and Tuset, J. J. 2009. Characterization and pathogenicity of Fusicladium eriobotryae, the fungal pathogen responsible for loquat scab. Plant Dis. 93:11511157.

To characterize the fungal pathogen responsible for loquat scab and establish differences in pathogenicity in loquat, eight strains identified as Fusicladium eriobotryae were isolated from either loquat leaves or fruit showing scab symptoms in Spain. Loquat plants belonging to the $\mathrm{cv}$. Peluche were infected via a newly developed infection system that was based on spraying susceptible loquat plants with fungal spore suspensions, keeping the plants for 1 week in 100\% humidity, and then transferring the plants to ambient relative humidity in greenhouses. Scab symptoms were analyzed and pathogenic characterization of all $F$. eriobotryae strains revealed different degrees of aggressiveness. Based on infection progression and severity of scab symptoms, strain ST1 was confirmed as the most aggressive in cultivars in the Mediterranean region. Strain ST1, which even caused chlorotic spots in loquat stems, is so aggressive it can be used to identify highly resistant cultivars using this in vivo system. Molecular characterization of internal transcribed spacer ribosomal DNA and, particularly, the glyceraldehyde 3-phosphate dehydrogenase gene, clearly distinguished loquat strains from Venturia inaequalis. Moreover, random amplified polymorphic DNA (RAPD) and microsatellite-primed polymerase chain reaction techniques were used to qualitatively discriminate between species and report the variations within fungal populations. Molecular variability was checked by comparing all the different strains and enabled the specific identification of $F$. eriobotryae. Although no association was observed between any pattern and phenotypic traits, such as aggressiveness, RAPD provided a specific profile that allowed fungal identification.
\end{abstract}

Cultivation of loquat (Eriobotrya japonica Lindl.) is widespread in the subtropical regions of Southern China, Japan, Northern India, Israel, and the Mediterranean $(6,15,17,32)$. Many diseases have been reported to attack loquat. In Europe, two problems damage the fruit rinds (6): sunburn ("purple spot"), a physiological disorder directly related to calcium content in the fruit tissues, and fungal black spot (18), which is an important problem because it downgrades fruit quality.

Loquat scab, also known as fungal black spot, is widespread throughout the Mediterranean region. This disease resembles apple and pear scab (caused by Venturia inaequalis and Venturia pyrina, respectively; 19) in nearly all aspects. Within the genus Venturia, 52 species have been described in the anamorphs Fusicladium, Spilocaea, and Cladosporium (27), most of which are pathogens of fruit trees or orna-

Corresponding author: P. Sánchez-Torres

E-mail: sanchez_paltor@gva.es

* The $e$-Xtra logo stands for "electronic extra" and indicates that Figure 2 appears in color online.

Accepted for publication 5 July 2009.

doi:10.1094/PDIS-93-11-1151

(C) 2009 The American Phytopathological Society mental plants. Loquat is highly susceptible to scab and the symptoms appear throughout flower and fruit development, with the most serious damage occurring in leaves and fruit during wet seasons when control measures are inadequate. Scabby fruit is unsuitable for market, resulting in significant economic losses. This situation is notable in the Mediterranean area, where the most extensive loquat-growing region in Spain is located $(6,32)$.

Although loquat scab is a wellrecognized problem in this region, reports are mostly based on symptom description, and little is known about how this disease develops or which is the main fungal pathogen responsible for causing it. Some authors attribute loquat scab to Spilocaea spp. while others cite Fusicladium spp., both as synonyms of Fusicladium pomi that is considered an anamorph of $V$. inaequalis $(25,26)$. The main trait distinguishing between both anamorphs concerns conidiogenous cell proliferation, with sympodial proliferation being characteristic of the genus Fusicladium and percurrent proliferation corresponding to the genus Spilocaea (25). Nevertheless, previous studies have confirmed the presence of both types of proliferation in Fusicladium spp. (22). Moreover, taxonomic characterization reported for the genus Fusicladium suggests that separating certain Venturia anamorphs into several genera cannot be maintained $(2-4,25)$. Thus, distinction between the different anamorphs of the genus Venturia remains controversial because it is not supported by molecular evidence.

In most eukaryotic organisms, ribosomal DNA (rDNA) comprises copies arranged in tandem repeats. Many taxonomic studies of fungi have been based on the rDNA repeat $(7,12)$. In fact, rDNA analyses in Venturia spp. confirmed the presence of an intron and internal transcribed spacer ITS1 allele, providing a genetic marker to subdivide $V$. inaequalis populations. This has proven valuable in determining the relationship between Venturia spp. $(13,14,24)$ and, recently, rDNA characterization has been employed to explain phylogenetic relationships within species of the genus Venturia, which causes scab on tree fruit crops $(24,28)$. Moreover, different polymerase chain reaction (PCR)-based assays have been developed which can discriminate between species both accurately and rapidly. In this sense, digestion of the complete ITS region exhibited a pattern that allows $V$. nashicola, responsible for Japanese pear scab, to be distinguishable from other related species (13). Also, random amplified polymorphic DNA (RAPD) markers $(10,34)$ and microsatellite-primed PCR $(11,31)$ are used to differentiate between numerous fungal plant pathogens and determine genetic variation within fungal populations (16).

Molecular characterization of fungal pathogens responsible for scab and pathogenesis in loquat have not been reported previously. To better understand the infection process, differences in aggressiveness are important. In this work, we describe an infection system that enabled us to track the progress of infection and measure disease severity. Hence, the aims of this work are to (i) characterize the pathogen via molecular approaches, (ii) determine differences in pathogenesis in loquat strains, and (iii) specifically identify loquat species via molecular techniques.

\section{MATERIALS AND METHODS}

Isolates. The fungal strains used in this study are listed in Table 1. Part of the cultures were obtained from the Centraalbureau voor Schimmelcultures (CBS) in Utrecht, The Netherlands. Eight different strains (ST1, CA1, CAC31, CAC32, 
CAC61, CAC62, FE40, and FE41) were isolated from leaves and fruit of two loquat cultivars present in the Mediterranean region, Tanaka and Algerie, and hybrids (Algerie $\times$ Changzhong) all displaying scab symptoms. Two more strains from loquat (E5 and E6), kindly provided by Dr. Le Cam (UMR de Pathologie Végétale, Institut National de la Recherche Agronomique, France), were used in this work. Fungi were isolated by serial growth in water-agar medium; then, pure colonies were grown on potato dextrose agar (PDA) amended with streptomycin at $100 \mu \mathrm{g} / \mathrm{ml}$ to avoid bacterial contamination. All strains and progeny were maintained on PDA at $4^{\circ} \mathrm{C}$.

Fungal identification. Several portions of 15-day-old actively growing mycelium were morphologically examined on PDA and malt extract agar (MEA) plates. Fungal material was examined using distilled water or lactophenol-cotton blue as the mounting media, and characteristics compared with those described previously $(5,25,26)$.

For growth comparisons, loquat strains were grown on PDA plates at $21^{\circ} \mathrm{C}$ and colony diameter was measured over time. Three replicates were carried out per each strain.

Pathogenicity assays. An in vivo infection system was performed to reproduce loquat scab symptoms. Conidia were collected by scraping 1-month-old cultures with a sterile spatula and transferring conidia to sterile water. Conidia were then filtered and the concentration determined with a hemacytometer, then adjusted to $10^{5}$ conidia/ml in sterile water with $0.5 \%$ Tween 20. Spore suspension $(20 \mathrm{ml})$ was applied by spraying to cover the leaves. Rootstock loquat plants of the cv. Peluche, $25 \mathrm{~cm}$ in height and presenting young leaves of 5 to $7 \mathrm{~cm}$ in length, were used for inoculation, having previously been proven susceptible to scab. Plants had young leaves, no more than $7 \mathrm{~cm}$ long, because this size is the most susceptible to infection. Fifteen plants were inoculated with each strain. Control plants were sprayed with water and $0.5 \%$ Tween 20 . All plants were kept in a chamber at $100 \%$ relative humidity for 1 week and afterward in a greenhouse at $20^{\circ} \mathrm{C}$ and ambient relative humidity. Quantification of necrotic areas was done visually, estimating percent of affected leaf area by counting necrotic spots per leaf. The severity of disease was assessed according to the percentage of necrotic leaf area. Disease severity of each strain was rated on a 0 -to- 4 scale 45 days after inoculation, in which $0=$ no scab symptoms, $1 \geq 20 \%$ necrotic leaf area, $2=$ 21 to $40 \%$ necrotic leaf area, $3=41$ to $60 \%$ necrotic leaf area, and $4 \geq 61 \%$ necrotic leaf area. All strains were assayed in two independent experiments.

DNA extraction. Each isolate was initially grown on PDA plates for at least 21 days at $21^{\circ} \mathrm{C}$. DNA was isolated as previously described (13), with minor modifications. The eluted DNA was stored at $-20^{\circ} \mathrm{C}$ in Tris-EDTA buffer (1 mM Tris- $\mathrm{HCl}, 10$ mM EDTA, pH 7.5) and used as the template for further PCR reactions.

rDNA amplifications. Molecular identification of all fungal strains used was

Table 2. Sequence of oligonucleotides used in this study

\begin{tabular}{ll}
\hline Oligo name $^{\mathbf{a}}$ & \multicolumn{1}{c}{ Sequence } \\
\hline ITS1 & 5'-TCCGTAGGTGAACCTGCGG-3' \\
ITS4 & 5'-TCCTCCGCTTATTGATATGC-3' \\
G3PD-For & 5'-TCGGTCGTATTGGACGTATC-3' \\
G3PD-Rev & 5'-GACCTTGGCCATGTATGCTA-3' \\
Pari1 & 5'-CTGCTTGGCACAGTTGGCTTC-3' \\
PGO2 & 5'-GGCACTGAGG-3' \\
PI06 & 5'-AAGGCGGCAG-3' \\
Pnor1 & 5'-ACCGCTACGCCGGCACTCTCGGCAC-3' \\
Pomt1 & 5'-GTGGACGGACCTAGTCCGACATCAC-3' \\
Ppen & 5'-TGCCGAGCTG-3' \\
\hline
\end{tabular}

${ }^{\mathrm{a}}$ ITS = internal transcribed spacer and G3PD = glyceraldehyde 3-phosphate dehydrogenase. based on sequences of the ITSs (ITS- 1 and ITS-2) of rDNA. Primers ITS1 and ITS4 (33) that amplify the first ITS (ITS1), the 5,8 rRNA gene, and the second ITS region (ITS2) (Table 2) were used for fungal identification. PCR reactions were performed in a total volume of $50 \mu$ containing $1 \mu \mathrm{l}$ (20 to $60 \mathrm{ng}$ ) of template DNA, $1 \mu \mathrm{M}$ each primer, $200 \mu \mathrm{M}$ each dNTP, and $1.25 \mathrm{U}$ of Taq DNA polymerase (Invitrogen, Carlsbad, CA). Cycling parameters were $94^{\circ} \mathrm{C}$ for $5 \mathrm{~min}$; followed by 30 cycles of $94^{\circ} \mathrm{C}$ for $30 \mathrm{~s}, 55^{\circ} \mathrm{C}$ for $45 \mathrm{~s}$, and $72^{\circ} \mathrm{C}$ for 1 min; with a final extension of $72^{\circ} \mathrm{C}$ for 10 min. Amplification products were analyzed by electrophoresis through $1.0 \%$ agarose in Tris-acetate EDTA (TAE) buffer $(40 \mathrm{mM}$ Tris-acetate, $2 \mathrm{mM}$ EDTA, $\mathrm{pH}$ 8.0). To gain a greater understanding of the issue, molecular analyses were carried out within ITS rDNA sequences of loquat isolates. Furthermore, a study was made of the relationship between loquat isolates and other tree fruit-related species, such as $V$. inaequalis, $F$. carpophilum, Spilocaea pomi, and V. pyrina.

Glyceraldehyde 3-phosphate dehydrogenase gene amplification. Primers glyceraldehyde 3-phosphate dehydrogenase (G3PD)-For and G3PD-Rev (Table 2) were designed based on sequences pre-

Table 1. Fungal strains used in this study

\begin{tabular}{|c|c|c|c|c|c|c|}
\hline Fungal species & Origina $^{a}$ & Strain & Host & Aggressiveness $^{b}$ & rDNA $^{c}$ & G3PDd $^{d}$ \\
\hline Fusicladium carpophilum & CBS 497.62 & $\mathrm{Fc}$ & Prunus sp. & n.e. & EU035426 & EU744580 \\
\hline Venturia pyrina & CBS 331.65 & $\mathrm{Vp}$ & Pyrus sp. & n.e. & EU035469 & EU744582 \\
\hline Spilocaea pomi & CBS 180.47 & $\mathrm{Sp}$ & Unknown & n.e. & EU282481 & EU744581 \\
\hline$V$. inaequalis & CBS 595.70 & $\mathrm{Vi}-1$ & Malus sylvestris & 0 & EU282477 & EU744576 \\
\hline V. inaequalis & CBS 476.61 & Vi-2 & M. sylvestris & 0 & EU282478 & EU744577 \\
\hline V. inaequalis & CBS 593.70 & $\mathrm{Vi}-3$ & M. sylvestris & 0 & EU282479 & EU744578 \\
\hline V. inaequalis & CBS 813.69 & Vi-4 & M. sylvestris & 0 & EU282480 & EU744579 \\
\hline S. eriobotryae & $I N R A$ & E5 & Eriobotrya japonica & 2 & EU282473 & EU744574 \\
\hline S. eriobotryae & INRA & E6 & E. japonica & 1 & EU282474 & EU744575 \\
\hline F. eriobotryae & This study & ST1 & E. japonica & 4 & EU282468 & EU744566 \\
\hline F. eriobotryae & This study & CA1 & E. japonica & 2 & EU282467 & EU744567 \\
\hline F. eriobotryae & This study & CAC31 & E. japonica & 1 & EU282469 & EU744568 \\
\hline F. eriobotryae & This study & CAC 32 & E. japonica & 3 & EU282470 & EU744569 \\
\hline F. eriobotryae & This study & CAC61 & E. japonica & 3 & EU282471 & EU744570 \\
\hline F. eriobotryae & This study & CAC62 & E. japonica & 1 & EU282472 & EU744571 \\
\hline F. eriobotryae & This study & FE40 & E. japonica & 3 & EU282475 & EU744572 \\
\hline F. eriobotryae & This study & FE41 & E. japonica & 2 & EU282476 & EU744573 \\
\hline
\end{tabular}

a CBS: Culture Collection (Cetraalbureau voor Schimmelcultures, Utrecht, The Netherlands).

${ }^{b}$ Aggressiveness is shown as the disease severity of each strain, rated on a 0-to-4 scale 45 days after inoculation; n.e.= not evaluated in this work.

c Accession number of internal transcribed spacer sequence.

d Accession number of glyceraldehyde 3-phosphate dehydrogenase (G3PD) gene sequence. 
sent in databases and were used to amplify the G3PD gene from the different fungal isolates. Cycling parameters were $94^{\circ} \mathrm{C}$ for $5 \mathrm{~min}$; followed by 30 cycles of $94^{\circ} \mathrm{C}$ for $30 \mathrm{~s}, 58^{\circ} \mathrm{C}$ for $45 \mathrm{~s}$, and $72^{\circ} \mathrm{C}$ for $1 \mathrm{~min} 30$ $\mathrm{s}$; with a final extension of $72^{\circ} \mathrm{C}$ for 10 min. Amplification products were analyzed by electrophoresis in $1.0 \%$ agarose in TAE buffer.

DNA sequencing. PCR products were purified using the Ultra Clean PCR Clean-up (MoBio, Solana Beach, CA) and then sequenced using primers ITS1, ITS4, G3PD-For, or G3PD-Rev. DNA sequencing was performed using the fluorescent chain-terminating dideoxynucleotides method (21) and an ABI 377 sequencer (Applied Biosystems, Madrid, Spain). DNA sequences were compared with those from the EMBL database with the Washington University-Basic Local Alignment Search Tool (WU-BLAST) algorithm (1).

Phylogenetic analysis. To obtain a more accurate view of the identity and phylogenetic relationships of the strains, a phylogenetic reconstruction was performed by maximum parsimony method conducted in MEGA4 (30), resampling data with 1,000 bootstrap replicates (9). The percentage of bootstrap replicate that yielded each grouping was used as a measure of statistical confidence, considering as significant values above $90 \%$.

RAPD fingerprinting. Six different primers-Pari1, Pnor1, Pomt1(10), PG2, PI06 (8), and Ppen (20) (Table 2) -were used in PCR reactions in a total volume of $50 \mu \mathrm{l}$ containing $1 \mu \mathrm{l}$ (20 to $60 \mathrm{ng}$ ) of genomic DNA, $1 \mu \mathrm{M}$ each primer, $200 \mu \mathrm{M}$ each dNTP, and 1.25 U of Taq DNA polymerase (Invitrogen). Cycling parameters were 30 cycles of $94^{\circ} \mathrm{C}$ for $30 \mathrm{~s}, 58^{\circ} \mathrm{C}$ for $45 \mathrm{~s}$, and $72^{\circ} \mathrm{C}$ for $1 \mathrm{~min}$, with a final extension of $72^{\circ} \mathrm{C}$ for $10 \mathrm{~min}$. Amplification products were analyzed by electrophoresis in $1.5 \%$ agarose in TAE buffer.

Microsatellite-primed PCR analysis. Amplification was performed using $(\mathrm{AAG})_{6},(\mathrm{CAG})_{5}$, and $(\mathrm{GTC})_{5}$ primers. PCR reactions were carried out in a total volume of $50 \mu \mathrm{l}$ containing $1 \mu \mathrm{l}(20 \mathrm{ng})$ of genomic DNA, $1 \mu \mathrm{M}$ each primer, $200 \mu \mathrm{M}$ each dNTP, and 1.25 U of Taq DNA polymerase (Invitrogen). Cycling parameters were 30 cycles of $94^{\circ} \mathrm{C}$ for $30 \mathrm{~s}, 48^{\circ} \mathrm{C}$ for $45 \mathrm{~s}$, and $72^{\circ} \mathrm{C}$ for $1 \mathrm{~min}$, with a final extension of $72^{\circ} \mathrm{C}$ for $10 \mathrm{~min}$. Amplification products were analyzed by electrophoresis in 3\% agarose in TAE buffer.

\section{RESULTS}

Isolation and identification of loquat fungal strains. Loquat scab symptoms were mostly present on the leaves and fruit in the form of green to olive-brown spots. Among all the fungi present on loquat showing scab symptoms, Cladosporium spp. and Alternaria spp. were the most frequently isolated and, to a lesser extent,
Fusicladium spp. Both Cladosporium spp. and Alternaria spp. are normally saprophytic, being not responsible for loquat scab, and grow quickly, unlike Fusicladium spp., which grow more slowly and were more difficult to isolate.

After pure colonies of Fusicladium spp. had been isolated, fungal strains were incubated at $21^{\circ} \mathrm{C}$ for at least 4 weeks to allow conidiation. In vitro, all loquat isolates had olive-colored colonies without aerial mycelia. Mycelia were immersed, very rarely superficial. Given its subcuticular growth, the colony developed slowly, taking 6 weeks to reach an average of just 20 to $35 \mathrm{~mm}$ in diameter at $21^{\circ} \mathrm{C}$. Conidia are solitary, shape variable, ovoid to obpyriform, straight and 0-1 septated, and narrowly pointed or broadly rounded at the apex. Size varied (20 conidia measured) from $11.6 \pm 0.8 \times 6.2 \pm 0.6 \mu \mathrm{m}$ in young stages to $16.3 \pm 2.5 \times 6.3 \pm 0.4 \mu \mathrm{m}$ in mature stage. Germination requires high humidity; hence, conidial germination occurred next to trichomes where water concentration was high. The most frequently observed proliferating conidiogenous cells were of the percurrent (annellate) type although, in some cases, sympodial (denticulate) proliferating conidiogenous cells were also observed. Conidiophores varied from $9.6 \pm 2.0 \times 4.6$ $\pm 0.7 \mu \mathrm{m}$ (young) to $17.5 \pm 1.9 \times 4.4 \pm 0.5$ $\mu \mathrm{m}$ (mature). Percurrent proliferation appeared as numerous conspicuous annellations after conidial development and release.

Based on morphological traits, all isolates were preliminary identified as $F$. eriobotryae (this name will be used for all loquat strains isolated in this study). Apart from these isolates, two more fungal strains (E5 and E6) were used in this work. Both strains were also isolated from loquat and previously identified by the provider as S. eriobotryae. Nevertheless, morphologic characterization carried out among all strains did not show any differences between $F$. eriobotryae and $S$. eriobotryae strains apart from a slower growth rate for $S$. eriobotryae ones. Sympodial proliferation was also observed on $S$. eriobotryae isolates.
Fungal growth comparison. All different loquat-isolated strains were grown on PDA plates to establish differences in growth rate that could be related to differences in pathogenicity. ST1 displayed the fastest growth rate, followed by FE40 and CAC61, which did not exhibit strong differences with the other loquat strains, with the exception of E5 and E6, which clearly displayed a slower growth rate (Table 3).

Disease assessment. The 10 strains from diseased loquat and four different $V$. inaequalis strains were used in pathogenicity assays using Peluche loquat plants, as described in Experimental Procedures. The time course of disease progress was evaluated and differences among strains noted when symptoms first appeared. Disease ratings were taken 45 days after inoculation and the results of two independent experiments showed that all strains of $V$. inaequalis were unable to infect loquat cv. Peluche plants whereas $F$. eriobotryae isolates caused different degrees of scab symptoms. The pathogenic potential of $V$. inaequalis was confirmed by infecting apple plants (data not shown). In both experiments, ST1-infected plants exhibited the most severe scab symptoms, followed by CAC31, CAC61, and FE40 with high disease severity and CA1, E5, and FE41 with moderate disease symptoms (Fig. 1). The remaining isolates (E6, CAC32, and CAC62) were able to infect loquat but caused minimal disease because fewer leaves were diseased per plant.

Sporulation was located on both sides of the leaves on ST1-infected plants but only on the adaxial side for the remaining isolates. The timing of symptom development differed for highly virulent strains compared with less virulent strains. ST1infected plants exhibited first symptoms 21 days postinoculation (dpi) in the form of a few circular chlorotic spots, which progressively increased in number at 34 to 38 dpi. At this time, typical star-shaped spots were present, which increased in size and became olive-colored and velvety due to the production of conidia. At $45 \mathrm{dpi}$, ST1infected plants were completely damaged, meaning that almost $100 \%$ of symptomatic leaves were necrotic. Symptoms were

Table 3. Rate of growth of Fusicladium eriobotryae strains on potato dextrose agar plates at $21^{\circ} \mathrm{C}^{\mathrm{a}}$

\begin{tabular}{lccccc}
\hline & \multicolumn{5}{c}{ Culture diameter $(\mathbf{m m})$} \\
\cline { 2 - 6 } Strains & $\mathbf{7 ~ d p i}$ & $\mathbf{1 3} \mathbf{~ d p i}$ & $\mathbf{2 7} \mathbf{~ d p i}$ & $\mathbf{3 5} \mathbf{~ d p i}$ & $\mathbf{4 0} \mathbf{d p i}$ \\
\hline ST1 & $3.73 \pm 0.68$ & $8.33 \pm 0.76$ & $22.50 \pm 0.50$ & $32.67 \pm 0.58$ & $37.00 \pm 0.01$ \\
CA1 & $2.23 \pm 0.40$ & $7.50 \pm 1.32$ & $17.67 \pm 3.06$ & $28.00 \pm 1.00$ & $31.00 \pm 0.05$ \\
CAC31 & $2.73 \pm 0.40$ & $9.00 \pm 0.02$ & $19.67 \pm 0.58$ & $26.83 \pm 0.29$ & $32.33 \pm 0.29$ \\
CAC32 & $3.83 \pm 0.29$ & $9.33 \pm 0.58$ & $20.83 \pm 0.29$ & $29.00 \pm 0.02$ & $32.00 \pm 0.04$ \\
CAC61 & $3.07 \pm 0.12$ & $8.83 \pm 0.29$ & $21.67 \pm 0.29$ & $28.67 \pm 0.29$ & $33.17 \pm 0.29$ \\
CAC62 & $3.05 \pm 0.14$ & $8.17 \pm 0.29$ & $19.33 \pm 0.58$ & $27.33 \pm 0.58$ & $31.00 \pm 1.73$ \\
FE40 & $2.00 \pm 0.00$ & $8.83 \pm 0.29$ & $23.33 \pm 0.76$ & $30.00 \pm 0.01$ & $34.00 \pm 0.05$ \\
FE41 & $3.04 \pm 0.11$ & $7.67 \pm 0.58$ & $18.67 \pm 0.58$ & $25.00 \pm 1.00$ & $28.00 \pm 1.00$ \\
E5 & $1.17 \pm 0.29$ & $3.33 \pm 0.58$ & $8.67 \pm 1.15$ & $15.33 \pm 2.31$ & $18.69 \pm 2.89$ \\
E6 & $1.30 \pm 0.29$ & $4.50 \pm 0.58$ & $10.50 \pm 1.15$ & $17.30 \pm 2.27$ & $19.20 \pm 2.76$ \\
\hline
\end{tabular}

${ }^{a}$ Results are the mean of three replicas and errors are indicated as standard deviation of the mean; dpi $=$ days postinoculation in which culture diameter was measured. 
delayed when less virulent strains were used, with the first chlorotic spots starting to appear at $30 \mathrm{dpi}$. At $45 \mathrm{dpi}$, spots were brown, with sporulation only on the leaf adaxial side, and the percentage of necrotic area was much lower (Fig. 2). In contrast, symptoms were quite severe for the most aggressive isolates, with ST1 F. eriobotryae strain being able to cause chlorosis on stems.
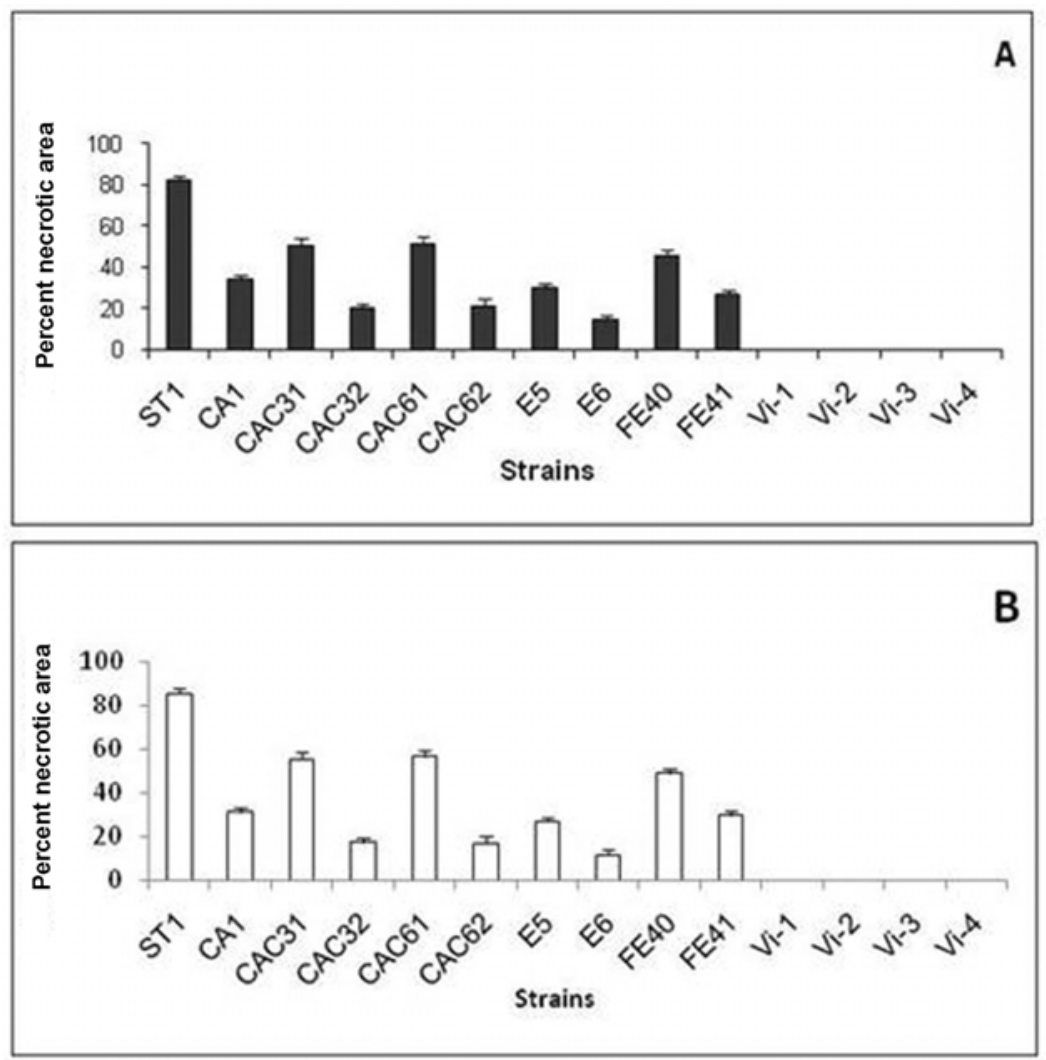

Fig. 1. Aggressiveness of Fusicladium eriobotryae and Venturia inaequalis strains on 'Peluche' loquat rootstocks. Percent necrotic leaf area of 15 plants per strain was assessed at 45 days post inoculation in $\mathbf{A}$ and $\mathbf{B}$, two independent experiments. Results are the mean of 15 replicate plants; standard deviation of the mean are indicated by bars.
Preliminary assays were also carried out with a few plants belonging to other cultivars, such as Tanaka, Algerie, or Zhanzhong, which displayed the same behavior as Peluche when inoculated with ST1 (data not shown), thus confirming previous results.

Molecular characterization of fungal isolates. The ITS amplification products did not display size differences among all analyzed strains. Sequence analysis of the ITS region did not reveal any significant differences among strains, apart from $V$. pyrina and $F$. carpophilum, which differed clearly (data not shown).

As a gene frequently used in phylogenetic analysis, sequence of the G3PD gene was carried out for all strains, revealing differences between loquat strains and $V$. inaequalis strains that separated both groups phylogenetically; moreover, it clearly distinguished $F$. carpophilum and $V$. pyrina from the other isolates. Phylogenetic analysis of the G3PD gene of all the strains sequenced in this study was performed using the maximum parsimony method together with sequences of other $V$. inaequalis retrieved from GenBank. The percentage of replicate trees in which the associated taxa clustered together in the bootstrap test are shown above the branches (Fig. 3). Topology resolved in this phylogeny grouped our loquat strains in a branch (with 99\% of bootstrap support), clearly separate from the rest of taxa of the genus included in this analysis, with the exception of $S$. pomi, which was included in the same group as the loquat strains.

RAPD fingerprinting. RAPD was performed for specific loquat strain identifica-
$\mathbf{A}$

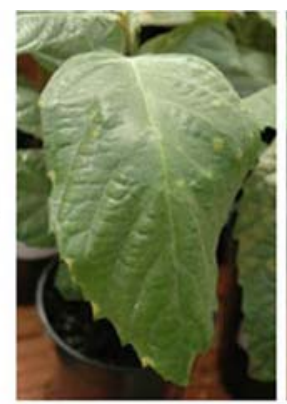

B

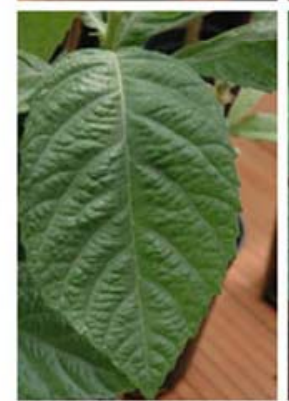

21 dpi

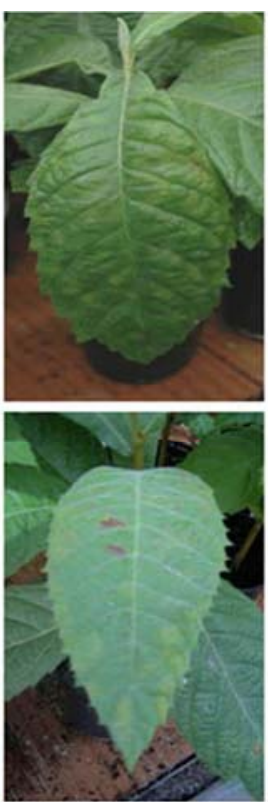

30 dpi
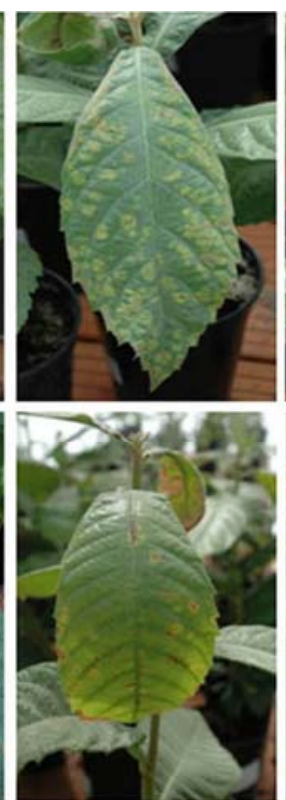

34 dpi
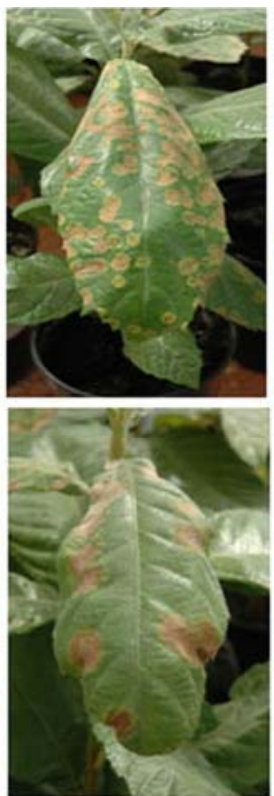

38dpi
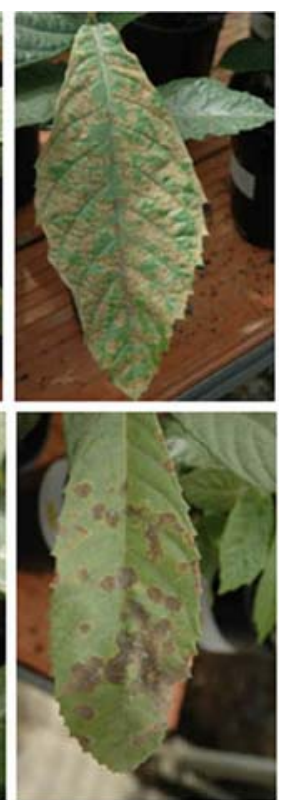

45 dpi

Fig. 2. Development of scab symptoms in loquat plants 'Peluche' inoculated with Fusicladium eriobotryae A, ST1 and B, CA1 isolates throughout 45 days of incubation. 
tion. Six different primers were used (See Experimental Procedures) from which only two, Pari1 and Pnor1, were suitable for further investigations and proved efficient for specific loquat-strain identification in three independent amplifications. The banding patterns when the Pari primer was used revealed specific DNA polymorphism for loquat isolates, $V$. inaequalis strains, and $S$. pomi, V. pyrina, and F. carpophilum (Fig. 4A). Although amplification with primer Pnor1 resulted in three different profiles within loquat strains ranging from E5 and E6 to CAC32 and FE41 and the other six $F$. eriobotryae, loquat strains could be distinguished from all four $V$. inaequalis strains tested and S. pomi, V. pyrina, and F. carpophilum, exhibiting a specific profile for each fungal group (Fig. 4B).

Microsatellite-primed PCR. Three different primers were screened for their ability to produce polymorphic bands within loquat strains. Only primer $(\mathrm{GTC})_{5}$ proved efficient in checking for genetic differences in all independent amplifications while the other two primers used were hardly specific (Fig. 5). This technique was able to differentiate strains from loquat, having two characteristic profiles, from the profiles of $V$. inaequalis, $V$. pyrina, S. pomi, and F. carpophilum. The two profiles correspond to strains from different geographical origins because E5 and E6 were loquat strains isolated in France and the remainder came from the Spanish Mediterranean region.

\section{DISCUSSION}

In this study, different Fusicladium strains isolated from loquat leaves and fruit, in addition to other saprophytic fungi, were identified at first as F. eriobotryae on the basis of morphological traits. This fungus has very slow mycelial development due to its subcuticular growth and, hence, when infection arises, it is only present in the epidermal tissue in the form of green-brown spots. These symptoms can become quite severe in the Mediterranean region.

The inclusion of this pathogen in the genus Fusicladium rather than the genus Spilocaea was based on a hypothesis put forward by certain authors, who suggested that the generic name Fusicladium should be conserved instead of Spilocaea (Hyphomycetes). Therefore, given its taxonomic age, Fusicladium is the most widely accepted name (2-4). Morphological characterization of E5 and E6 strains, previously identified as $S$. eriobotryae, exhibited typical percurrent as well as sympodial proliferations. Because of this fact, we consider that both fungal strains could actually correspond to the same species, particularly if all the abovementioned reasons are taken into consideration (26).

Pathogenicity studies carried out on isolates of F. eriobotryae and compared with other related species confirmed that the infection system developed by our group to reproduce scab symptoms is effective $(22,23)$. This in vivo infection system provides a reliable method for testing loquat cultivars with respect to tolerance or susceptibility to scab (35). Knowledge of the infection process could also lead to the development of new, more effective control methods in the near future.
A previous work demonstrated that a $V$. inaequalis strain (Vi-1) and F. carpophilum were unable to infect loquat plants, whereas $V$. pyrina and $S$. pomi gave rise to different types of scab symptom that differed from those caused by $F$. eriobotryae isolates $(22,23)$. In this work, the four different $V$. inaequalis strains used were unable to infect loquat plants although

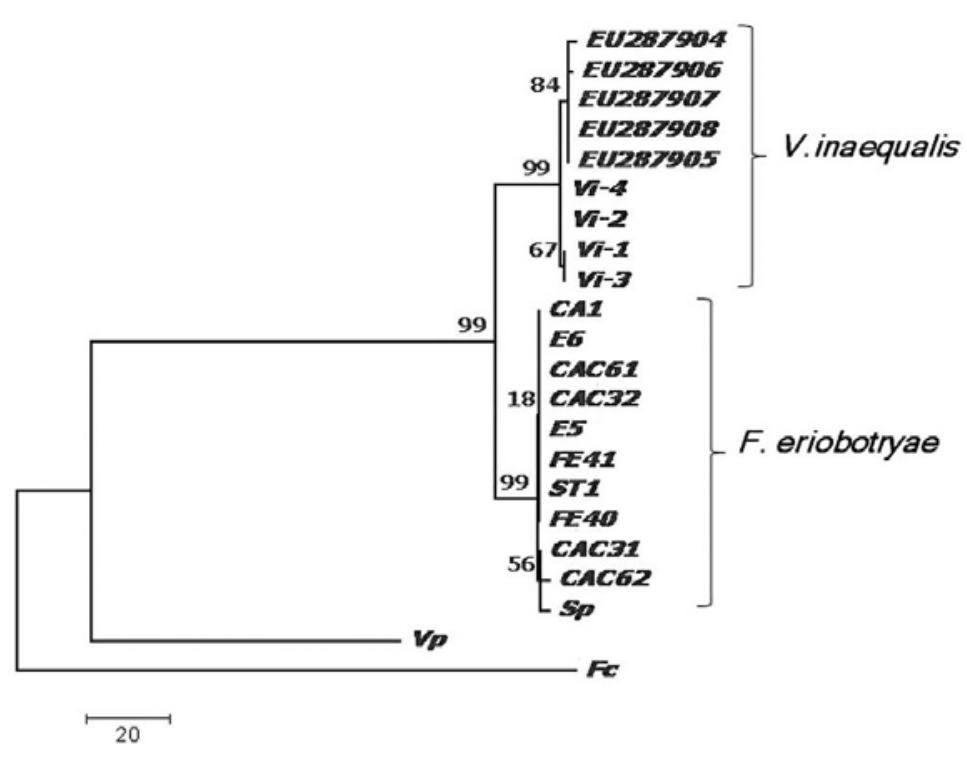

Fig. 3. Bootstrap tree generated using the maximum parsimony method among glyceraldehyde 3phosphate dehydrogenase DNA sequences from different Fusicladium eriobotryae, Venturia inaequalis, F. carpophilum $(\mathrm{Fc})$, V. pyrina $(\mathrm{Vp})$, and Spilocaea pomi $(\mathrm{Sp})$ strains. Percentages of replicate trees in which the associated taxa clustered together in the bootstrap test (values from 1,000 replicates over $50 \%$ ) are shown above the branches.
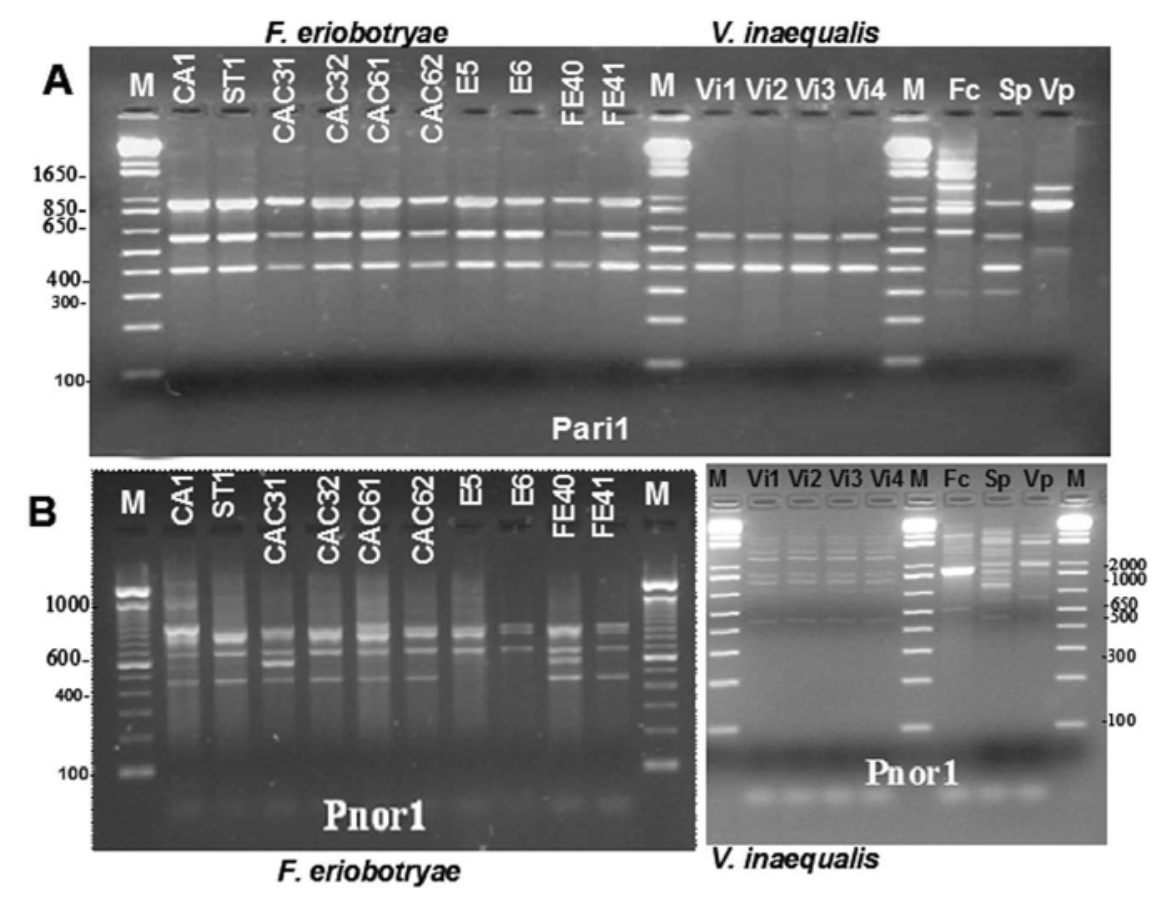

Fig. 4. Agarose gel of random amplified polymorphic DNA polymerase chain reaction products. Lane M, 100-bp molecular weight marker; lanes 1 to 6 correspond to Fusicladium eriobotryae strains (CA1, ST1, CAC31, CAC32, CAC61, and CAC62); lanes 7 and 8 correspond to Spilocaea eriobotryae strains E5 and E6 from France; lanes 9 and 10 correspond to F. eriobotryae strains FE40 and FE41; lanes 11 to 14 correspond to Venturia inaequalis strains $\mathrm{Vi}-1, \mathrm{Vi}-2, \mathrm{Vi}-3$, and $\mathrm{Vi}-4$; and lanes 15 to 17 correspond to F. carpophilum (Fc), S. pomi (Sp), and V. pyrina (Vp), respectively. A, Primer Pari1 and B, primer Pnor1. 
their ability to be pathogenic on apple plants was confirmed. Results obtained suggest different degrees of specificity, pointing to host specificity in the case of $F$. eriobotryae and V. inaequalis. In contrast, $V$. pyrina and $S$. pomi, which normally infect pear and apple, respectively (19), were also able to infect loquat; thus, they do not display specificity. Nevertheless, this fact has only been observed in experimental procedures in the greenhouse but not under natural conditions and, indeed, all isolates causing loquat scab were always identified as the named $F$. eriobotryae.

Differences in aggressiveness have been established according to leaf necrotic area and the number of leaves displaying scab symptoms. The time at which scab symptoms occur is an important indicator of aggressiveness because harmful isolates caused clear scab symptoms at $21 \mathrm{dpi}$ whereas less-aggressive isolates took longer to cause scab and did so less severely. Only ST1 was able to cause stem damage, confirming it to be more aggressive. Another high-aggressiveness trait was the presence of sporulation on both sides of leaves, which could speed up spore dispersion. Pathogenesis assays were performed on only one susceptible cultivar due to the availability of loquat plants. Nevertheless, preliminary assays in other loquat cultivars displayed the same pattern of aggressiveness. Pathogenetic differences displayed within loquat isolates highlight ST1 strain as the most aggressive and, hence, it is now being used for loquat resistance evaluation and to assess new control methods. Differences in pathogenicity can be considered in terms of fungal ability to penetrate intact loquat cuticles and form appressoria, as occurs in $V$. inaequalis (29). In contrast, no pathogenicity factors have been reported for $F$. eriobotryae so far but it seems feasible that it shares the same infection system.

Molecular characterization of rDNA clearly distinguished $V$. inaequalis from $F$. carpophilum, S. pomi, and $V$. pyrina, which are associated with scab in different fruit crops (19), confirming results by Le Cam $(13,14)$. Although the ITS region is commonly used for taxonomic studies $(7,13,24,28)$, in this study, differences were unable to distinguish between $V$. inaequalis isolates and fungal loquat strains. On expenses to this data we in principle consider $F$. eriobotryae and $V$. inaequalis to be the anamorph and teleomorph, respectively, following reported publications (26). Surprisingly, phylogenetic analysis of the G3PD gene clearly separate $F$. eriobotryae strains from $V$. inaequalis, establishing clear distances with $F$. carpophilum and $V$. pyrina. The inclusion of $S$. pomi in the same group as loquat strains suggest that this strain could be misidentified because molecular characterization proves it to be completely different from the rest of analyzed isolates and, therefore, it cannot be described as a synonym of $V$. inaequalis.

Microsatellite-primed PCR analysis strengthened the differences observed between $F$. eriobotryae and $V$. inaequalis and provided a specific profile for $F$. carpophilum, S. pomi, and V. pyrina. The two patterns observed within loquat isolates given by an extra band in E5 and E6 isolates could only indicate the presence of different races.

Microsatellite markers are reported to afford great advantages over RAPD or restriction fragment length polymorphism (31); however, here, RAPD has proven to be a useful molecular technique to distinguish isolates and exhibited good repro-

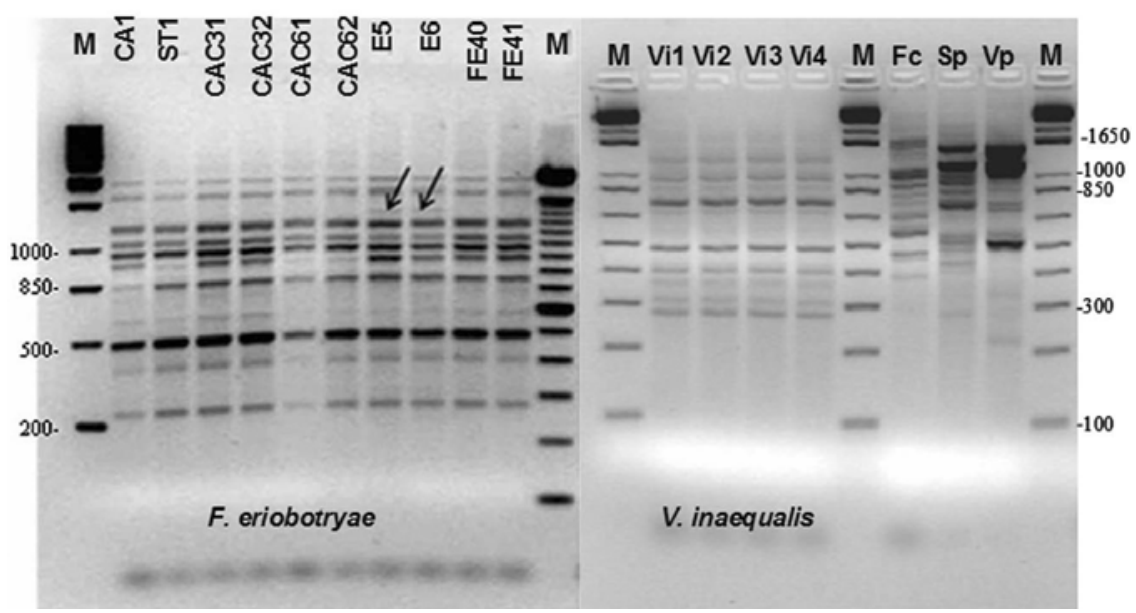

Fig. 5. Electrophoretic separation of polymerase chain reaction amplicons of 10 Fusicladium eriobotryae strains obtained using the microsatellite primer $(\mathrm{GTC})_{5}$. Arrows point to the extra band observed in Spilocaea eriobotryae strains E5 and E6 from France. Lanes 1 to 6 correspond to F. eriobotryae strains CA1, ST1, CAC31, CAC32, CAC61, and CAC62; lanes 7 and 8 correspond to S. eriobotryae strains E5 and E6; lanes 9 and 10 correspond to F. eriobotryae strains FE40 and FE41; lanes 11 to 14 correspond to Venturia inaequalis strains $\mathrm{Vi-1,}, \mathrm{Vi}-2, \mathrm{Vi}-3$, and $\mathrm{Vi}-4$; and lanes 15 to 17 correspond to $F$. carpophilum $(\mathrm{Fc}), S$. pomi $(\mathrm{Sp})$, and V. pyrina $(\mathrm{Vp})$, respectively. ducibility and high specificity. RAPD performed with primer Paril gave a specific profile for all loquat strains that could clearly be distinguished from isolates from fruit trees, such as V. inaequalis, F. carpophilum, S. pomi, and V. pyrina, which displayed a specific pattern.

All molecular data suggest that the fungus responsible for loquat scab is an anamorph of the genus Venturia but not an anamorph of $V$. inaequalis because it has been previously described and, hence, is not a synonym of $F$. pomi (26). This fungus should be renamed in order to be accurate from a taxonomic point of view.

This study revealed that morphological traits were not enough to establish differences between isolates, and molecular characterization as well as pathogenesis assays were necessary to establish the degree of aggressiveness and putative genetic variations.

Given that few sequences are available in the database related to loquat scab at present, this work provides the first molecular insight into the fungal pathogen causing loquat scab and outlines a good method for specific identification. This method could also be used to develop a diagnostic tool to identify the pathogen from infected host tissues without culturing the pathogen beforehand.

\section{ACKNOWLEDGMENTS}

This work was supported by funds from Instituto Valenciano de Investigaciones Agrarias (IVIA) of Spain. We thank B. Le Cam for providing E5 and E6 strains, M. Badenes for her valuable experience, and F. Barraclough for revision of the English text.

\section{LITERATURE CITED}

1. Altschul, S. F., Madden, T. L., Schäffer, A. A., Zhang, J., Zhang, Z., Miller, W., and Lipman, D. J. 1997. Gapped BLAST and PSI-BLAST: a new generation of protein database search programs. Nucleic Acids Res. 25:3389-3402.

2. Beck, A., Ritschel, A., Schubert, K., Braun, U. and Triebel, D. 2005. Phylogenetic relationships of the anamorphic genus Fusicladium s. lat. as inferred by ITS rDNA data. Mycol. Prog. 4:111-116.

3. Braun, U. 2005. Proposal to conserve Fusicladium against Cycloconium (Hyphomycetes) Taxon 54:538.

4. Braun, U., Ritschel, A., and Schubert, K. 2002. Proposal to conserve the generic name Fusicladium against Spilocaea (Hyphomycetes). Taxon 51:557.

5. Briosi, G., and Cavara, F. 1892. I Funghi Parassiti delle Piante Coltivate od Utili 186:7-8.

6. Caballero, P., and Fernández, M. A. 2002. Loquat, production and market. Options Mediterr. Ser. No. 58:11-20.

7. Campel, C. S., Donoghue, M. J., Baldwin, B. G., and Wojciechowski, M. 1995. Phylogenetic relationships in Maloideae (Rosaceae): evidence from sequences of internal transcribed spacers of nuclear ribosomal DNA and ITS congruence with morphology. Am. J. Bot. 83:903-918.

8. Dupont, J., Magnin, S., Marti, A., and Brousse, M. 1999. Molecular tools for identification of Penicillium starter cultures used in the food industry. Int. J. Food Microbiol. 49:109-118.

9. Felsenstein, J. 1985. Confidence limits on phylogenies: an approach using the bootstrap. Evolution 39:783-791. 
10. Geisen, R., Cantor, M. D., Hansen, T. K., Holzapfel, W. H., and Kaobsen, M. 2001. Characterisation of Penicillium roquefortii strains used as cheese starters cultures by RAPD typing. Int. J. Food Microbiol. 65:183191.

11. Guérin, F., Franck, P., Loiseau, A., Devaux, M., and Le Cam, B. 2004. Isolation of 21 new polymorphic microsatellite loci in phytopathogenic fungus Venturia inaequalis. Mol. Ecol. Notes 4:268-270.

12. Hillis, D. M., and Dixon, M. T. 1991. Ribosomal DNA: molecular evolution and phylogenetic inference. Q. Rev. Biol. 66:411-453.

13. Le Cam, B., Devaux, M., and Parisi, L. 2001. Specific polymerase chain reaction identification of Venturia nashicola using internally transcribed spacer region in the ribosomal DNA. Phytopathology 91:900-904.

14. Le Cam, B., Parisi, L., and Arene, L. 2002. Evidence of two formae speciales in Venturia inaequalis, responsible for apple and Pyracantha scab. Phytopathology 92:314-320.

15. Llácer, G., Martínez-Valero, R., Melgarejo, P., Romero, M., and Toribio, F. 1994. Present status and future prospects of underutilized fruit tree crops in Spain. Pages 63-75 in: First Meeting of CIHEAM Cooperative Research Network on Underutilized Fruit Trees, Zaragoza, Spain.

16. Ma, Z., and Michailides, T. J. 2005. Genetic structure of Botrytis cinerea populations from different host plants in California. Plant Dis. 89:1083-1089.

17. Morton, J. 1987. Loquat. Pages 103-108 in: Fruits of Warm Climates. J. F. Morton, ed. Creative Resource Systems, Inc., Miami, FL.

18. Ogawa, J. M., and English, H. 1991. Page 461 in: Disease of Temperate Zone Tree Fruit and Nuts Crops. J. M. Ogawa and H. English, eds.
Univ. Calif. Div. Agric. Nat. Resour. Publ. 3345, Oakland

19. Ohlendorf, B. 1999. In: Integrated Pest Management for Apples and Pears, 2nd ed. B. Ohlendorf, ed. Univ. Calif. Div. Agric. Nat. Resour. Publ. 3332, Oakland.

20. Pianzzola, M. J., Moscatelli, M., and Vero, S. 2004. Characterization of Penicillium isolates associated with blue mold on apple in Uruguay. Plant Dis. 88:23-28.

21. Prober, J. M., Trainor, G. L., Dam, R. J., Hobbs, F. W., Robertson, C. W., Zagursky, R. J., Cocuzza, A. J., Jensen, M. A., and Baumeister, K. 1987. A system for rapid DNA sequencing with fluorescent chain terminating dideoxynucleotides. Science 238:336-341.

22. Sánchez-Torres, P., Hinarejos, R., and Tuset J. J. 2007. Fusicladium eriobotryae: hongo causante del moteado del níspero en el Mediterráneo español. Bol. San. Veg. Plagas. 33:87-98.

23. Sánchez-Torres, P., Hinarejos, R., and Tuset J. J. 2007. Identification and characterization of Fusicladium eriobotryae: fungal pathogen responsible for loquat scab. Acta Hortic. 750:343-348.

24. Schnabel, G., Schnabel, E. L., and Jones, A. L. 1999. Characterization of ribosomal DNA from Venturia inaequalis and its phylogenetic relationship to rDNA from other tree-fruit Venturia species. Phytopathology 89:100-108.

25. Schubert, K., and Braun, U. 2005. Taxonomic revision of the genus Cladosporium s. Lat. Species reallocated to Fusicladium, Parastenella, Passalora, Pseudocercospora and Stenella. Mycol. Prog. 4:101-109.

26. Schubert, K., Ritschel, A., and Braun, U. 2003. A monograph of Fusicladium s. lat. (Hyphomycetes). Schlechtendalia 9:1-132.

27. Sivanesan, A. 1977. The taxonomy and pathol- ogy of Venturia species. In: Bibliotheca Mycologica. J. Cramer, ed. Vaduz, Liechtenstein.

28. Stehmann, C., Pennycook, A., and Plummer, K. M. 2001. Molecular identification of a sexual interloper: the pear pathogen, Venturia pyrina, has sex on apple. Phytopathology 91:633-641.

29. Steiner, U., and Oerke, E. C. 2007. Localized melanization of appressoria is required for pathogenicity of Venturia inaequalis. Phytopathology 97:1222-1230.

30. Tamura, K., Dudley, J., Nei, M., and Kumar, S. 2007. MEGA4: Molecular Evolutionary Genetics Analysis (MEGA) software version 4.0. Mol. Biol. Evol. 24:1596-1599.

31. Tenzer, I., degli Ivanissevich, S., Morgante, M., and Gessler, C. 1999. Identification of microsatellite markers and their application to population genetics of Venturia inaequalis Phytopathology 89:748-753.

32. Tous, J., and Ferguson, L. 1996. Mediterranean fruits. Pages 416-430 in: Progress in New Crops. J. Janick, ed. ASHS Press, Arlington, VA.

33. White, T. J., Bruns, T. D., Lee, S., and Taylor, J. 1990. Amplification and direct sequencing of fungal ribosomal RNA genes for phylogenetics. Pages 315-322 in: PCR Protocols: A Guide to Methods and Applications. M. A. Innis, D. H. Gelfand, J. J. Sninsky, and T. J. White eds. Academic Press, San Diego, CA.

34. Williams, J. G., Kubelik, A. R., Livak, K. J., Rafalski, J. A., and Tingey, S. V. 1990. DNA polymorphisms amplified by arbitrary primers are useful as genetic markers. Nucleic Acids Res. 18:6531-6535.

35. Yepes, L. M., and Aldwinckle, H. S. 1993. Pathogenesis of Venturia inaequalis on shoottip cultures and on greenhouse-grown apple cultivars. Phytopathology 83:1155-1162. 